Supplement for:

\title{
Temperature and VOC concentration as controlling factors for chemical composition of alpha-pinene derived secondary organic aerosol
}

L. N. Jensen ${ }^{1}$, M. R. Canagaratna ${ }^{2}$, K. Kristensen ${ }^{3}$, L. L. J. Quéléver ${ }^{4}$, B. Rosati1 ${ }^{1,5}$, R. Teiwes ${ }^{5}$, M. Glasius ${ }^{1}$, H. B. Pedersen ${ }^{5}$, M. Ehn ${ }^{4}$, M. Bilde ${ }^{1}$

${ }^{1}$ Department of Chemistry, Aarhus University, 8000 Aarhus C, Denmark

${ }^{2}$ Aerodyne Research, Inc., Billerica, MA, USA

${ }^{3}$ Department of Engineering, Aarhus University, 8000 Aarhus C, Denmark

${ }^{4}$ Institute for Atmospheric and Earth System Research - INAR / Physics, P.O. Box 64, FI-00014, University of Helsinki, Finland

${ }^{5}$ Department of Physics and Astronomy, Aarhus University, 8000 Aarhus C, Denmark

Correspondence to: Merete Bilde (bilde@chem.au.dk) 


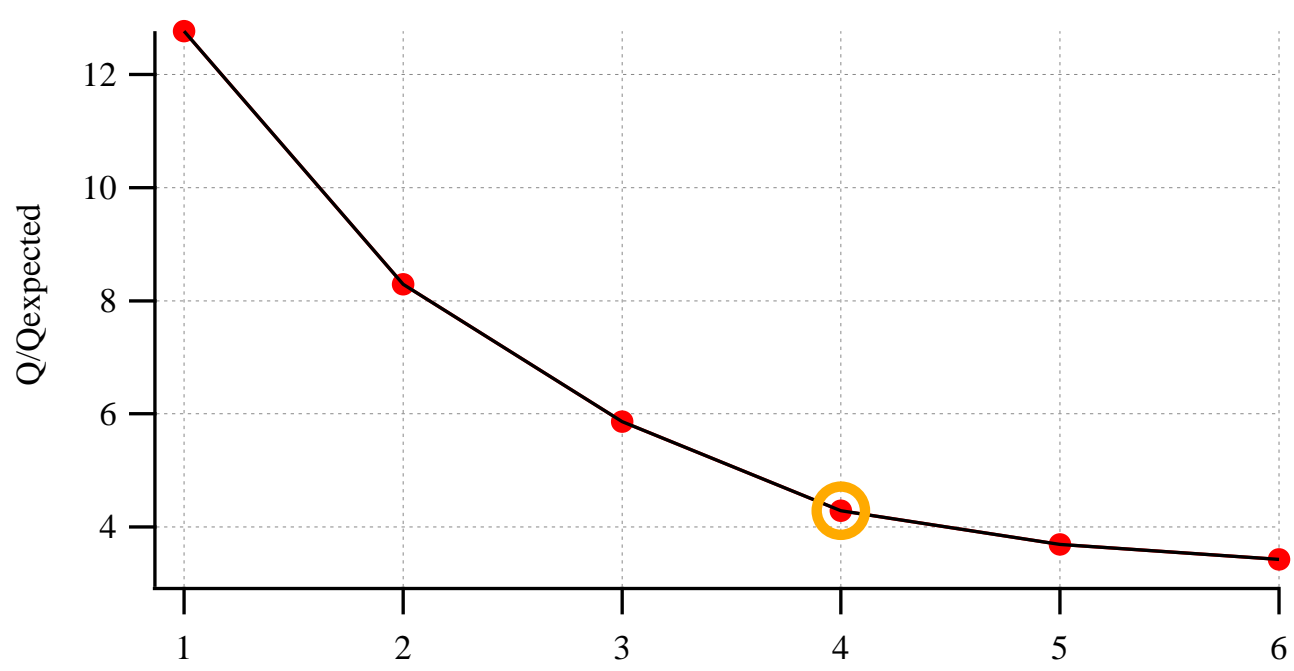

S1. Q/Q Q expected diagnostic plot from PMF analysis of the combined dataset of experiments 1-8. It shows that $\mathrm{Q} / \mathrm{Q}_{\text {expected }}$ of the four-factor solution is 4.3. For the five-factor and six-factor solutions it is slightly lower. 


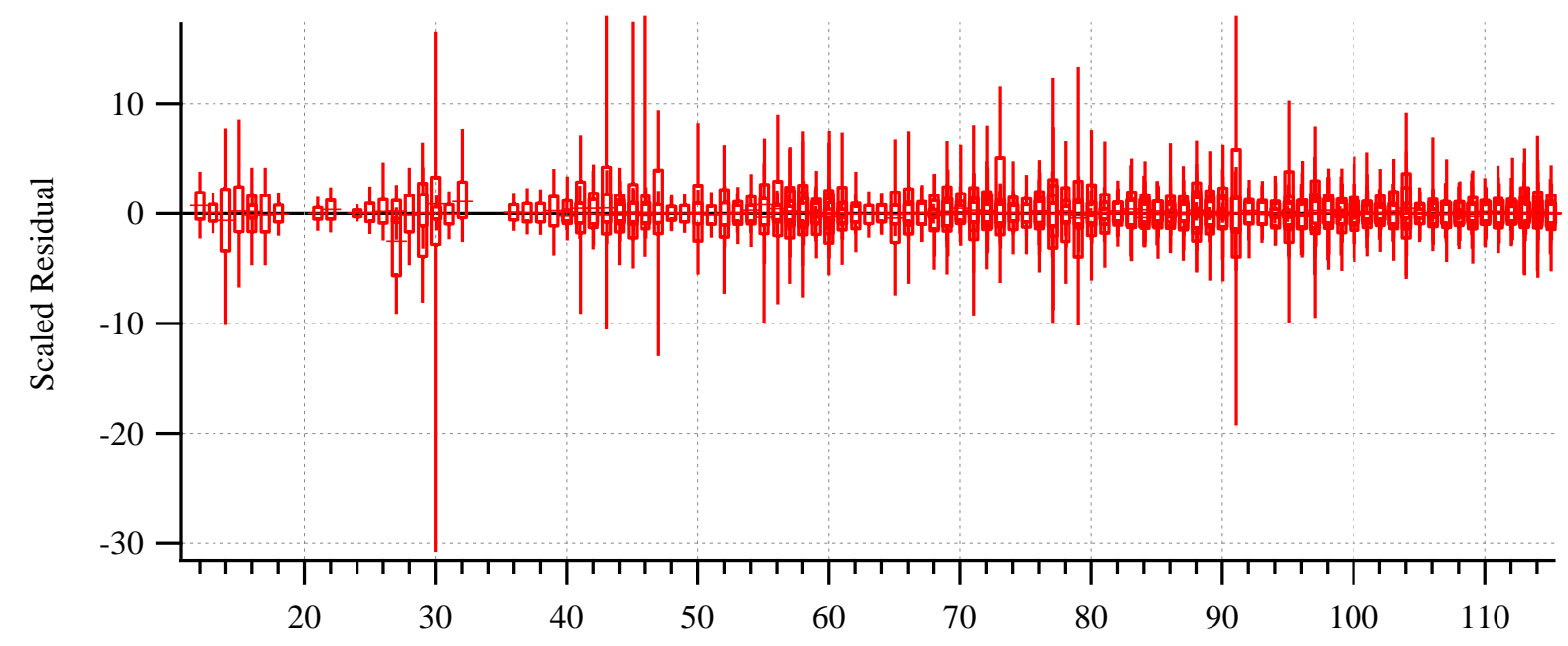

S2. Scaled residuals of all $\mathrm{m} / \mathrm{z}$ from the four-factor solution of the PMF analysis of the combined datasets of experiments $1-8$.

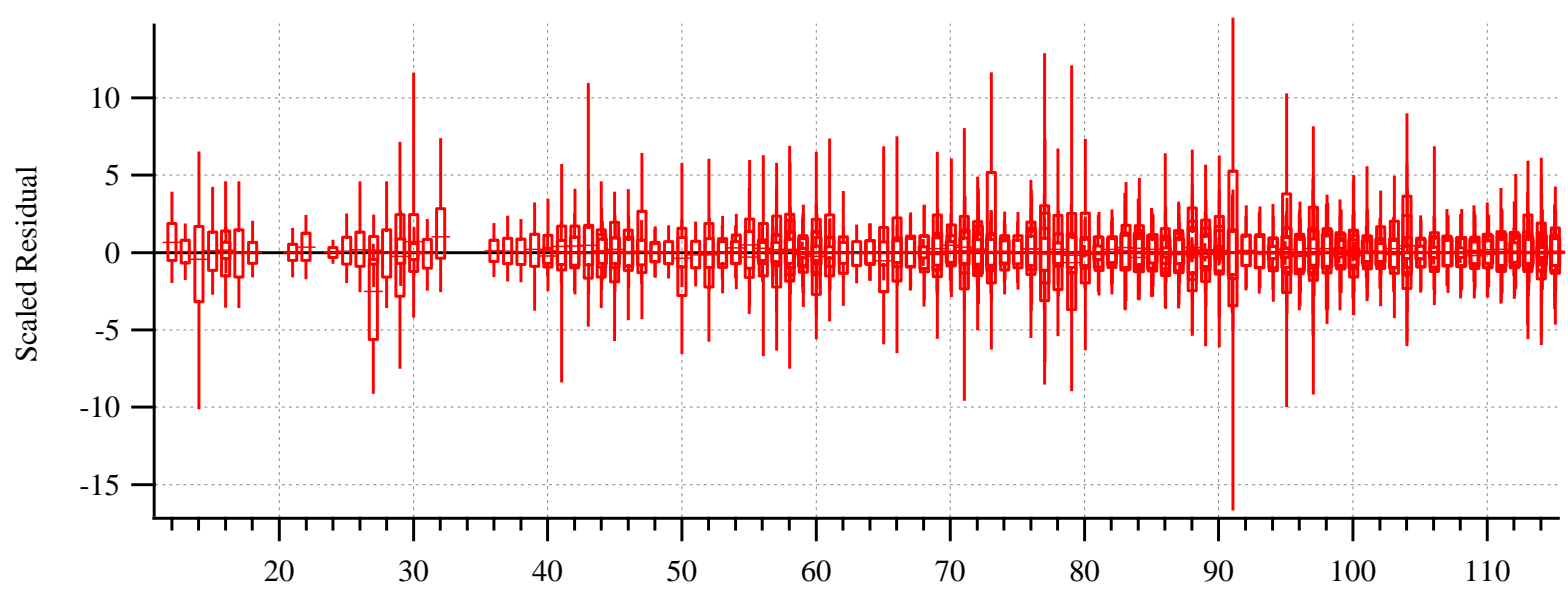

S3. Scaled residuals of all $\mathrm{m} / \mathrm{z}$ from the five-factor solution of the PMF analysis of the combined datasets of experiments $1-8$.

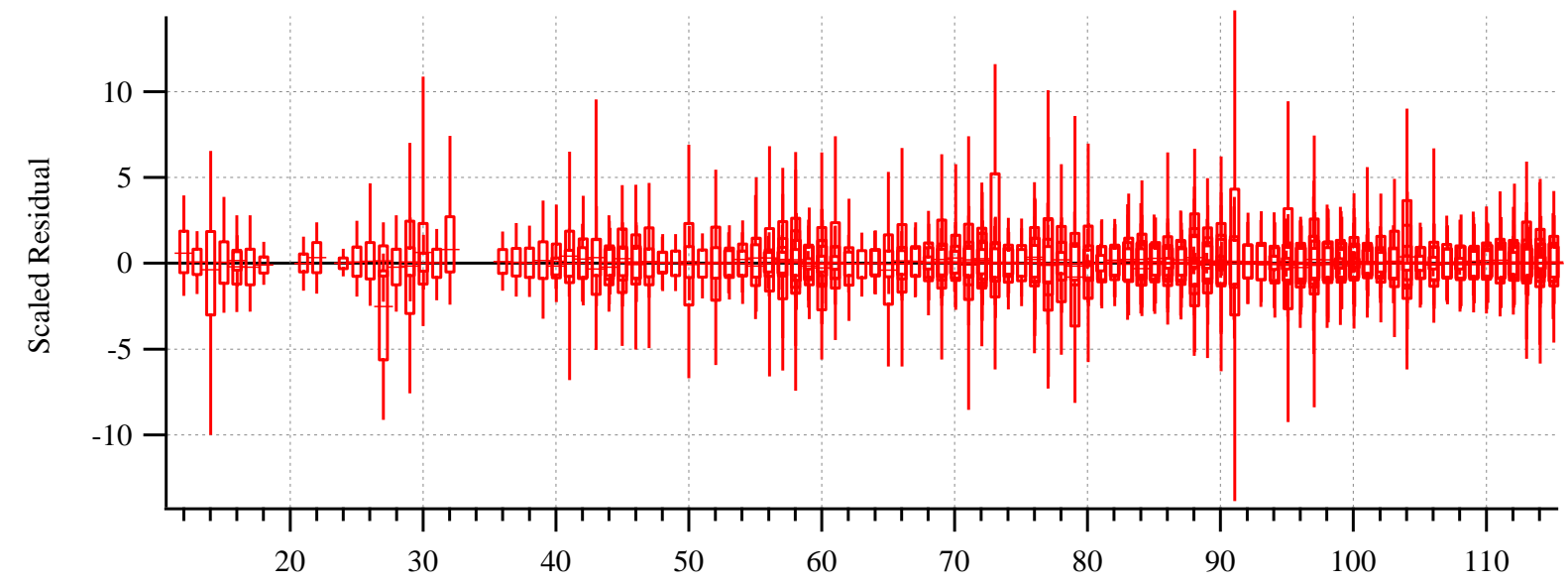

$\mathrm{S} 4$. Scaled residuals of all $\mathrm{m} / \mathrm{z}$ from the six-factor solution of the PMF analysis of the combined datasets of experiments $1-8$. 

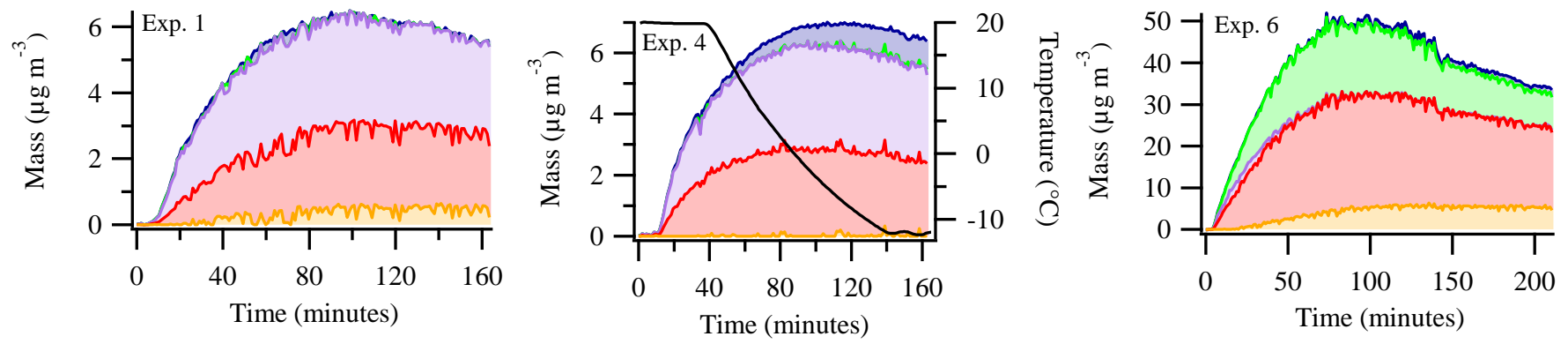

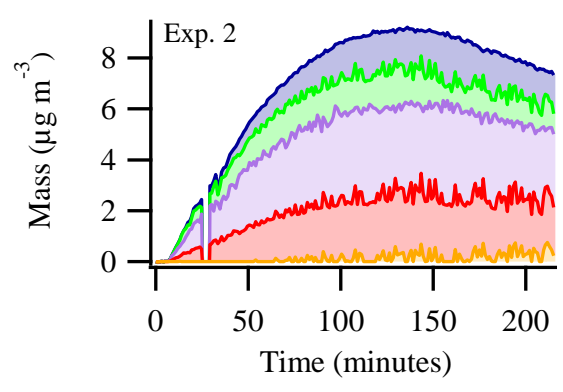

Factor 1

Factor 2

Factor 3

Factor 4

Factor 5

Temperature
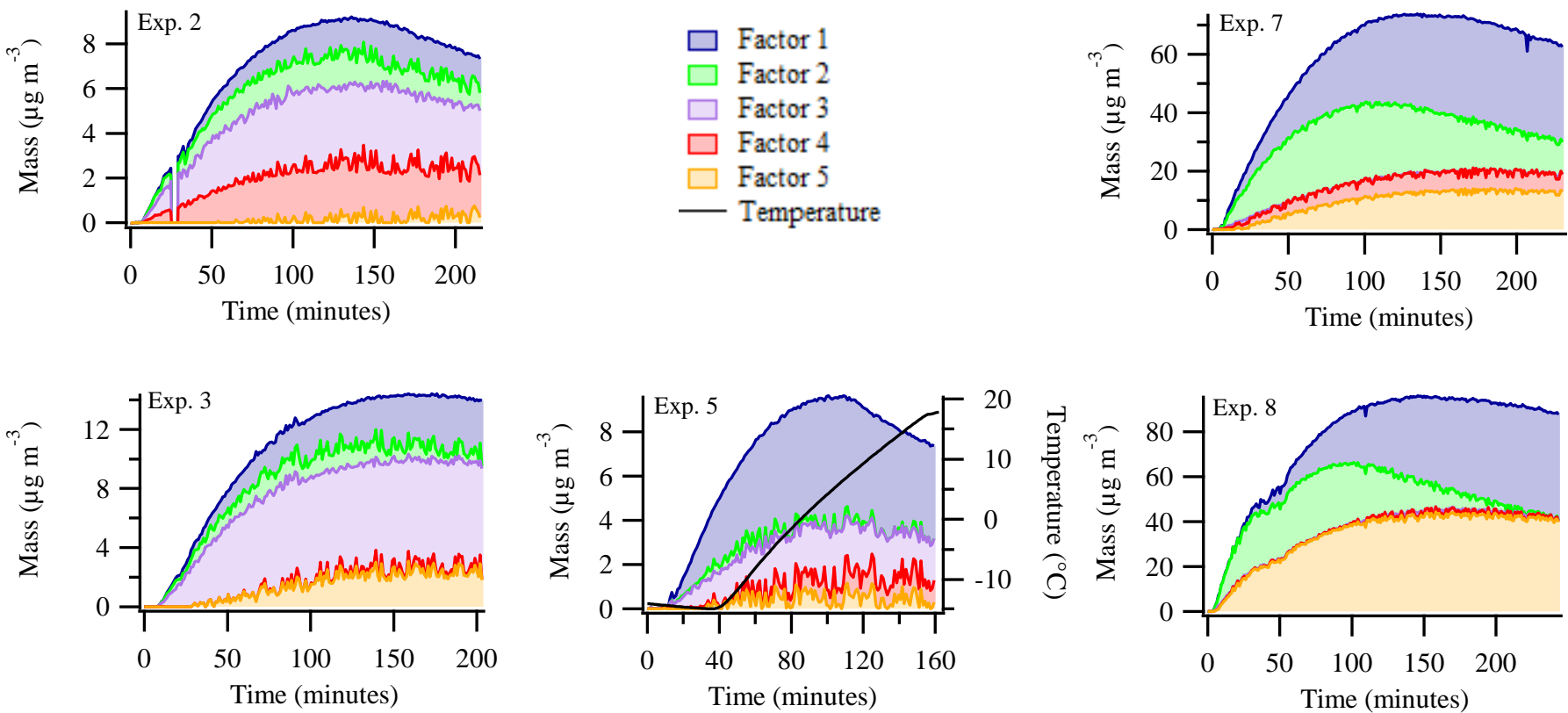
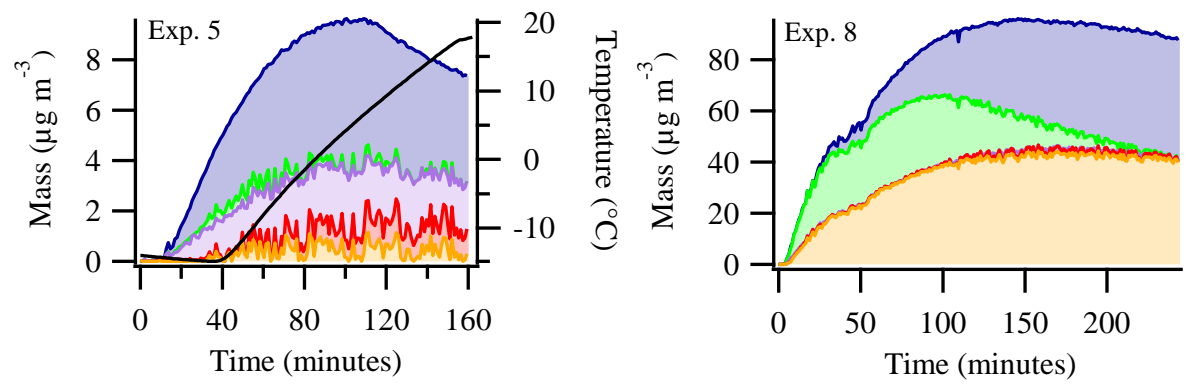

S5. Time series of five-factor solutions from PMF analysis of the combined datasets of experiments 1-8. 


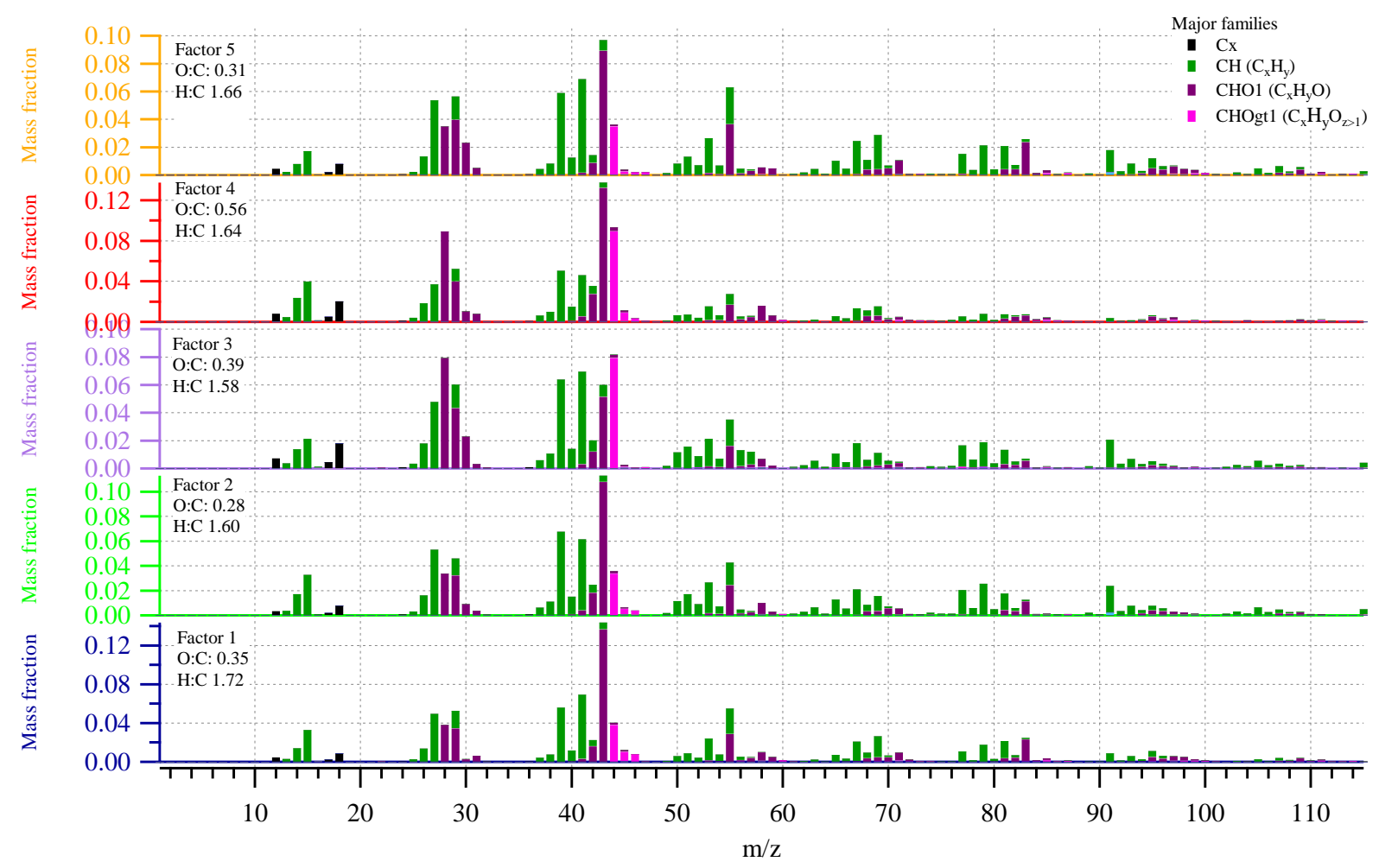

S6. Mass spectra of five-factor solution from PMF analysis of the combined datasets of experiments 1-8. 

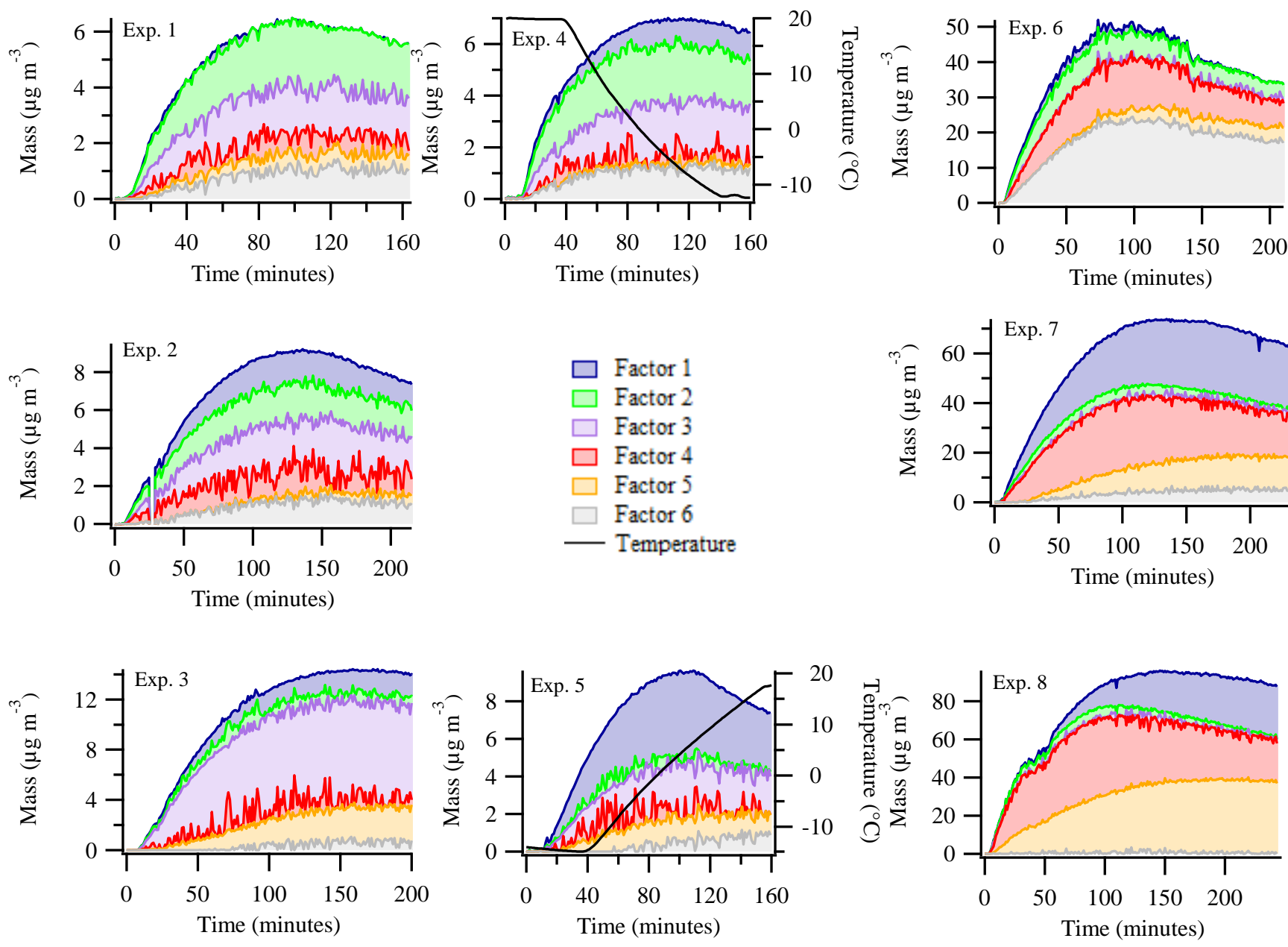

S7. Time series of six-factor solutions from PMF analysis of the combined datasets of experiments 1-8. 


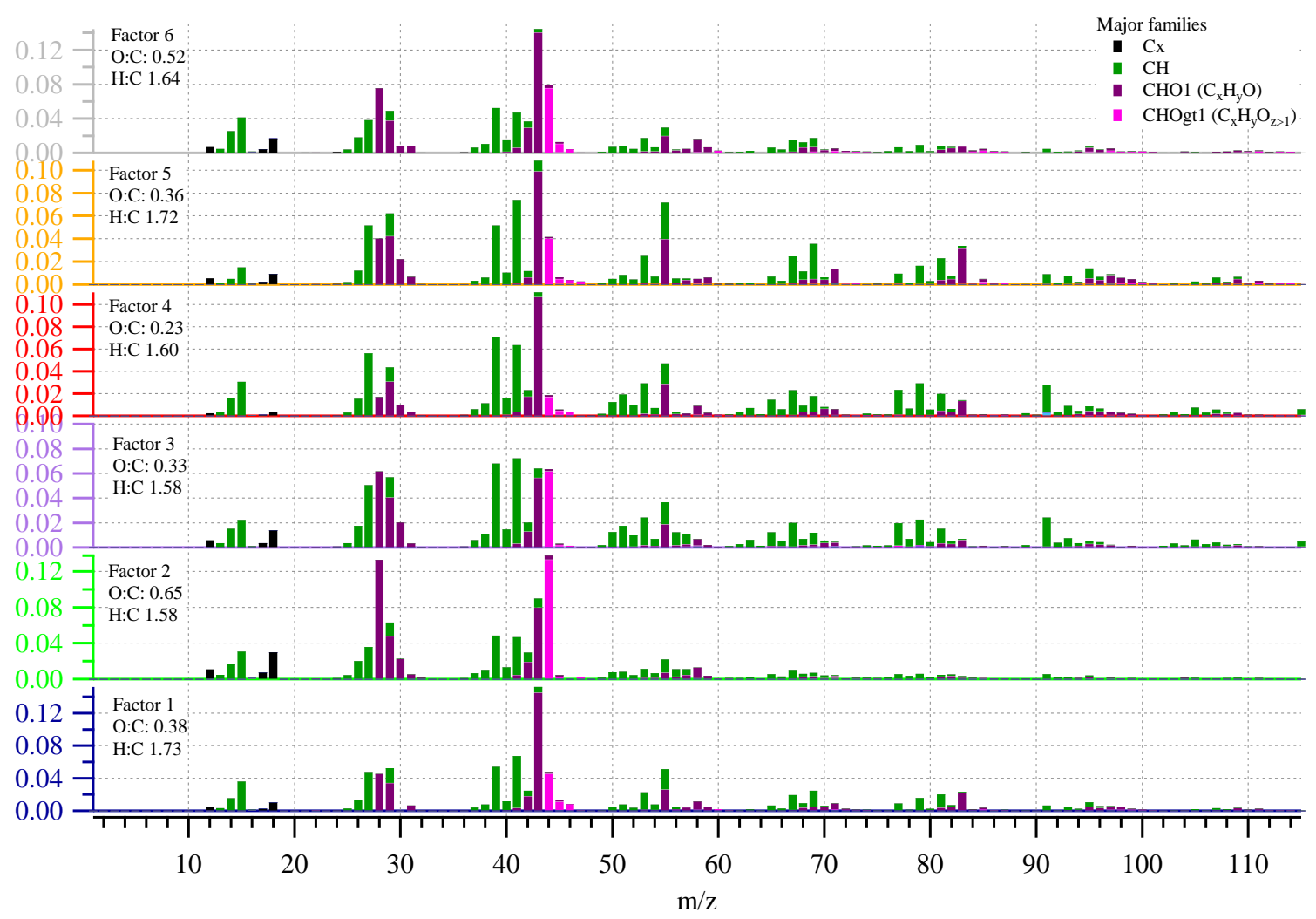

S8. Mass spectra of six-factor solution from PMF analysis of the combined datasets of experiments 1-8.

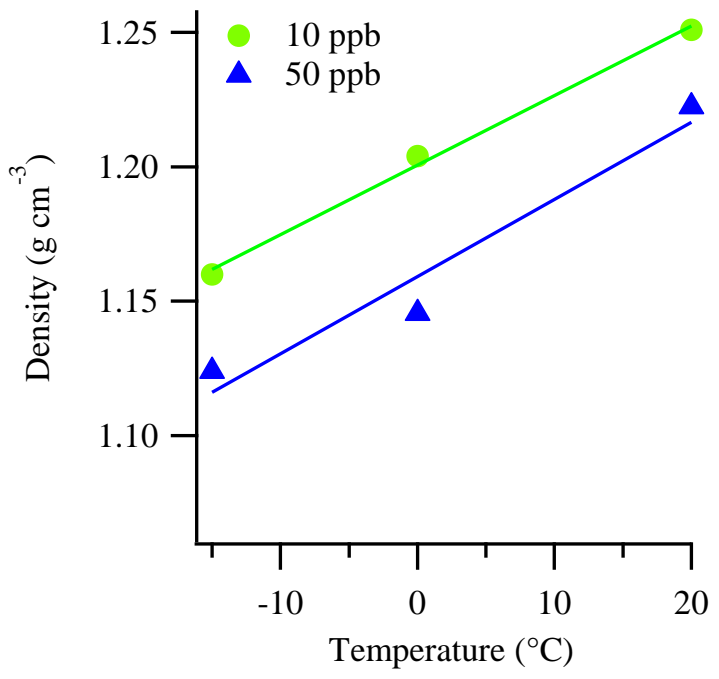

S9. The figure shows the density of the of SOA particles formed from 10 and $50 \mathrm{ppb} \alpha$-pinene, at 20, 0 , and -15 ${ }^{\circ} \mathrm{C}$, respectively (experiments 1-3 and 6-11). The values of the $50 \mathrm{ppb} \alpha$-pinene experiments are averages of two temperature series (experiments 6-8 and 9-11) each showing the same trend as the average. The densities are calculated from AMS data using the equation described by Kuwata et al. (2011). For each $\alpha$-pinene concentration straight lines are fitted to the densities at the three temperatures. In the $10 \mathrm{ppb}$ experiments the density increases with $0.0026 \mathrm{~g} \mathrm{~cm}^{-3}$ per degree Celsius and in the $50 \mathrm{ppb}$ experiments the density increases with $0.0029 \mathrm{~g} \mathrm{~cm}^{-3}$ per degree Celsius. 


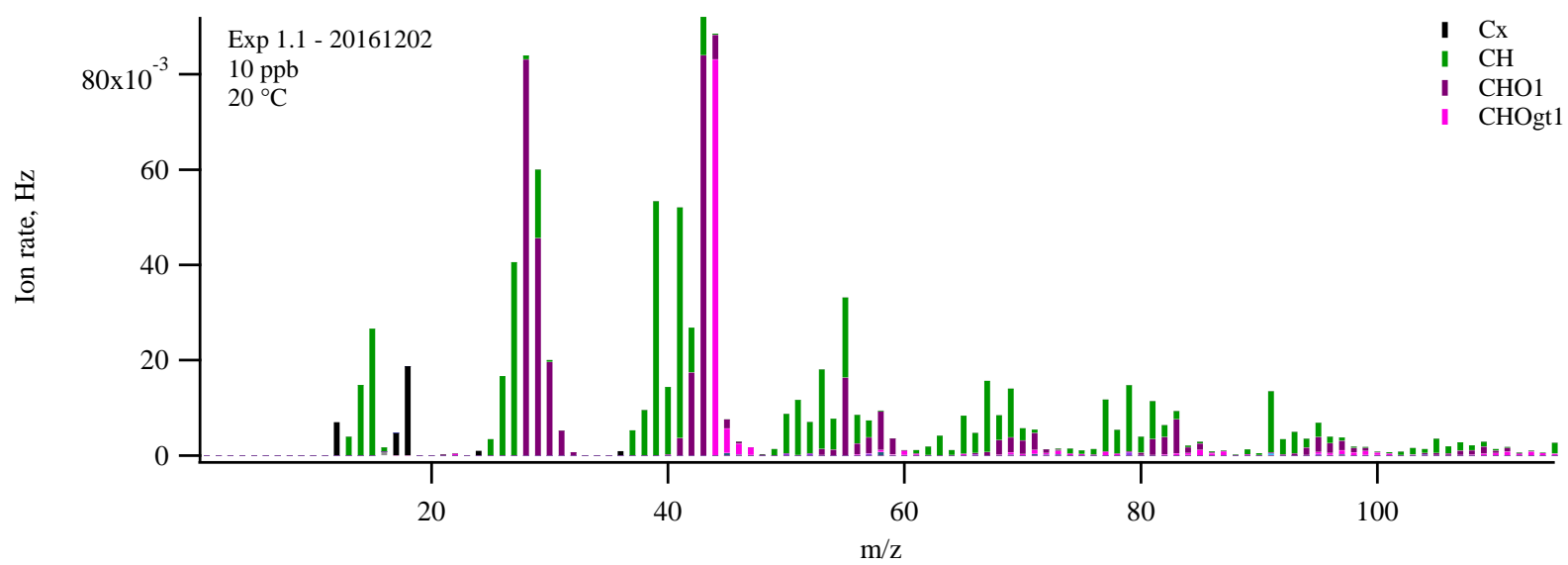

S10. High resolution mass spectrum of experiment 1.1 (based on a five minutes average at mass peak).

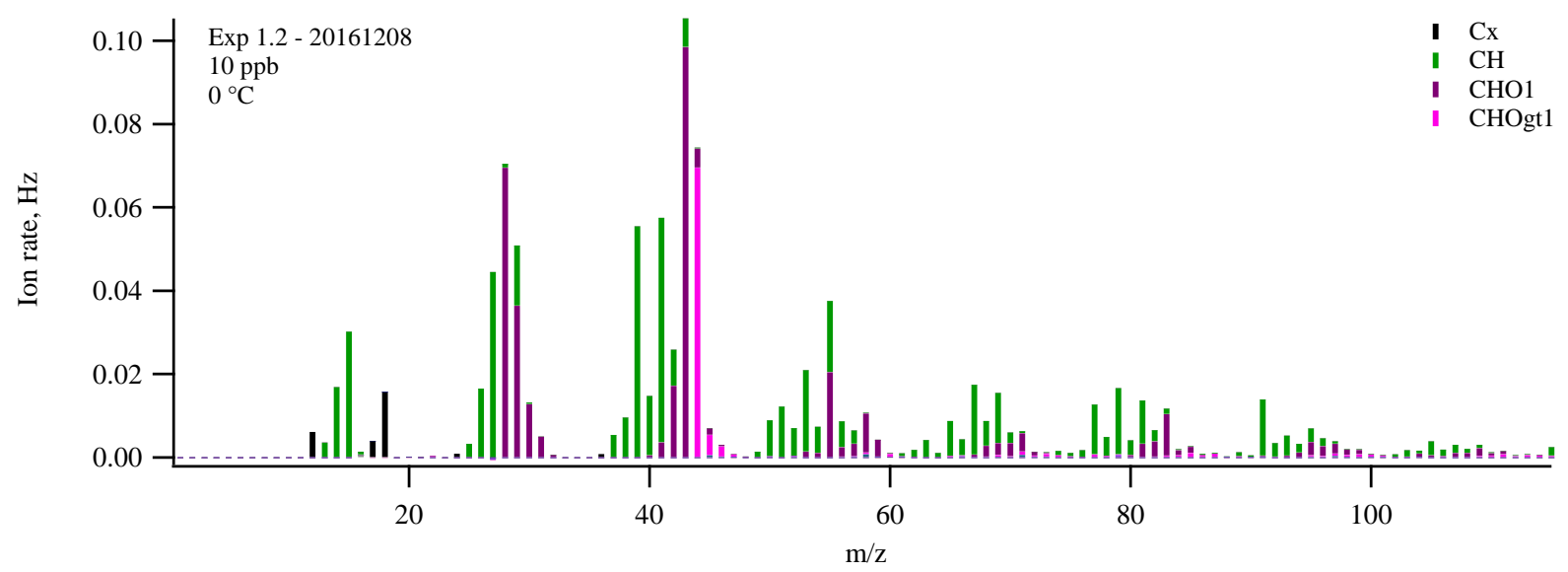

S11. High resolution mass spectrum of experiment 1.2 (based on a five minutes average at mass peak).

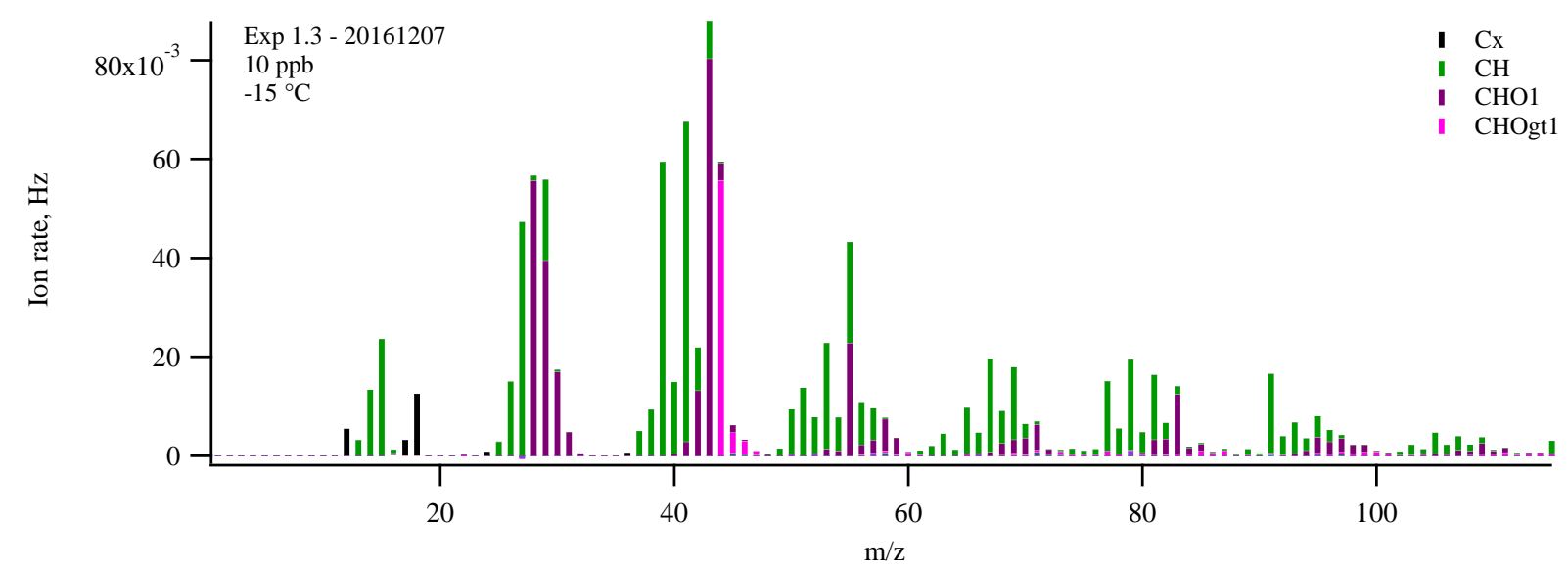

S12. High resolution mass spectrum of experiment 1.3 (based on a five minutes average at mass peak). 


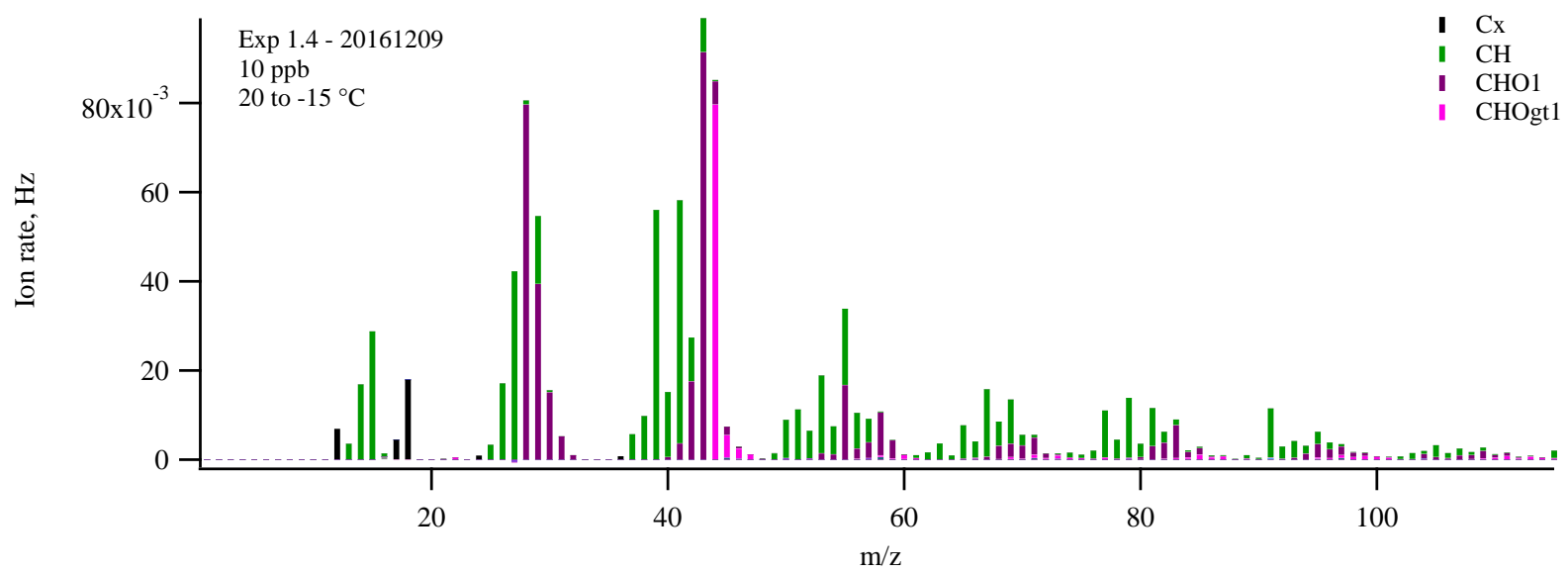

S13. High resolution mass spectrum of experiment 1.4 (based on a five minutes average at mass peak).

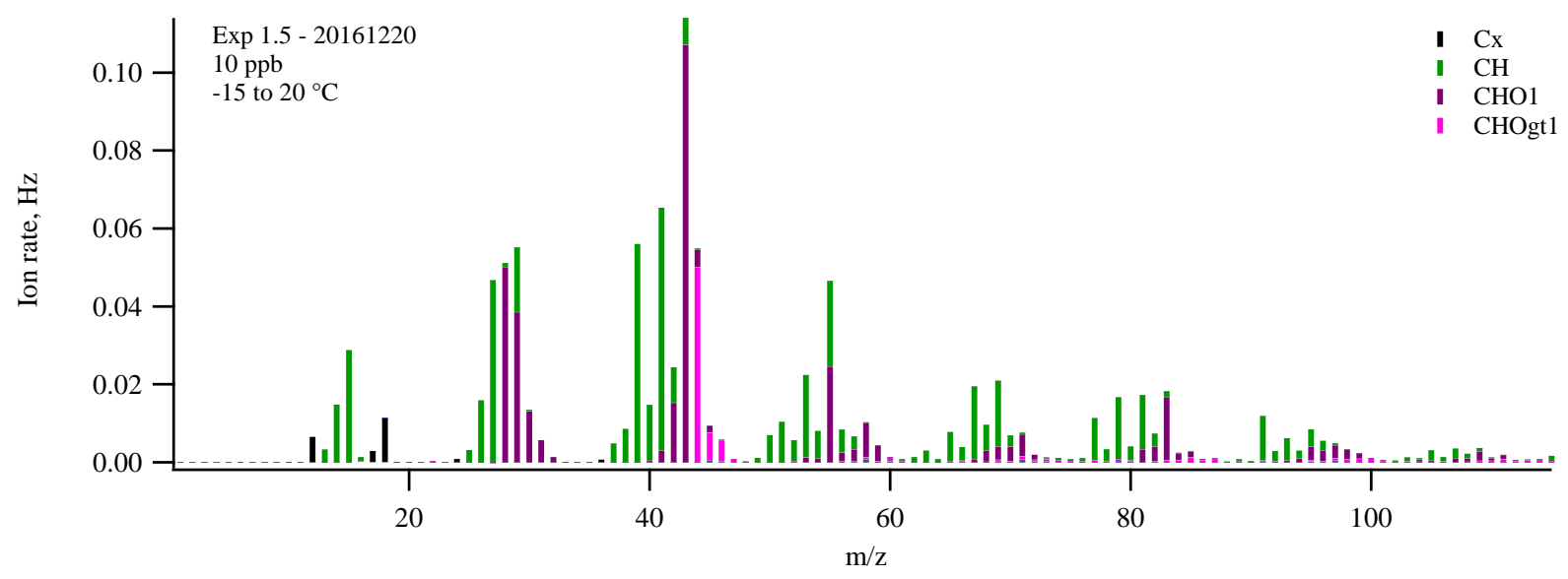

S14. High resolution mass spectrum of experiment 1.5 (based on a five minutes average at mass peak).

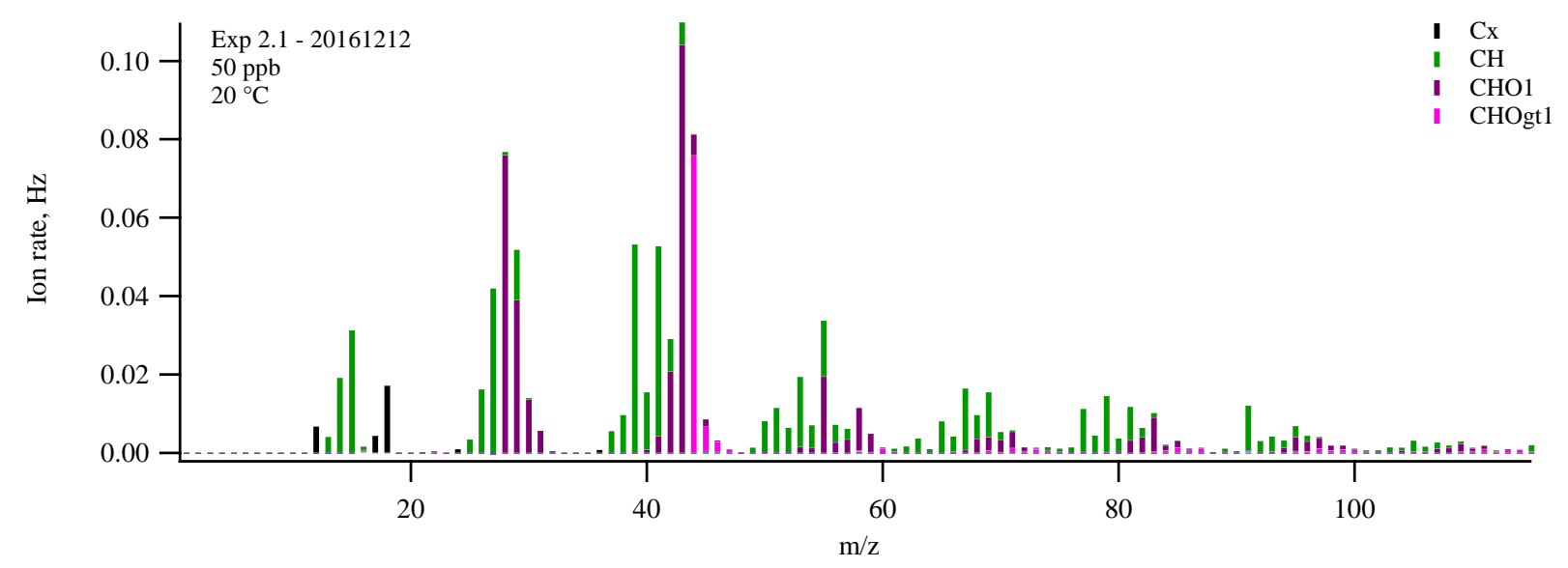

S15. High resolution mass spectrum of experiment 2.1 (based on a five minutes average at mass peak). 


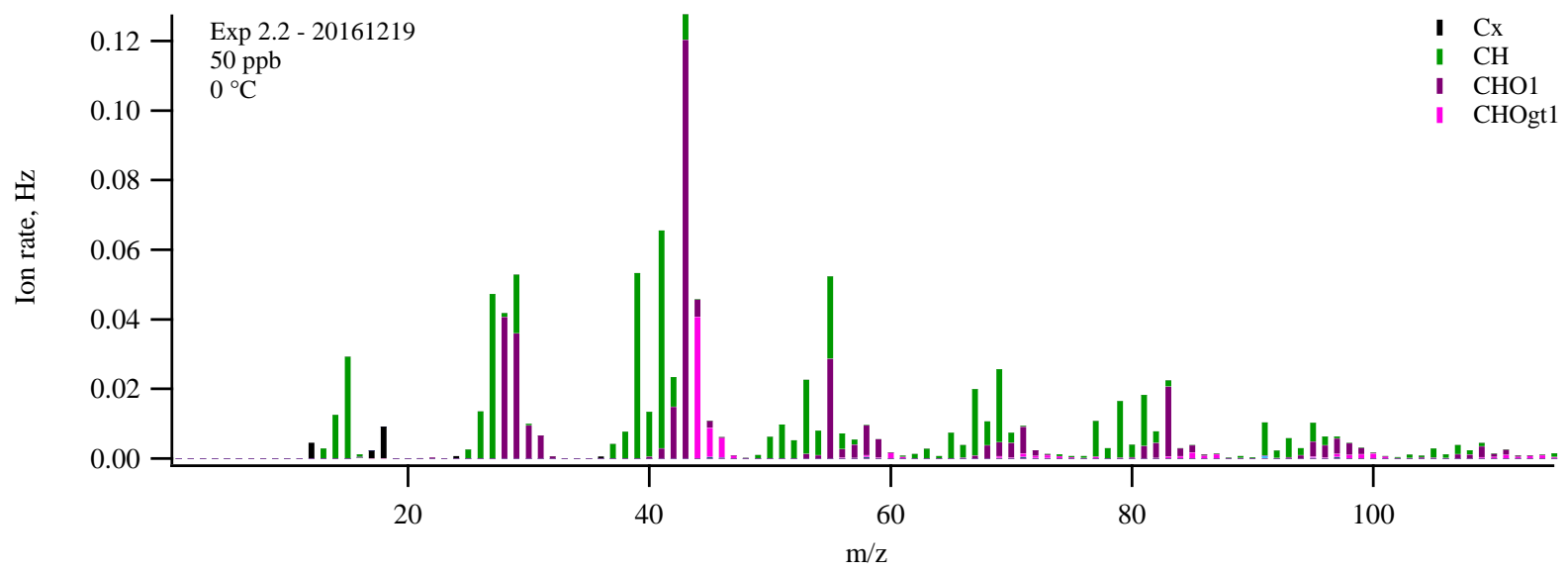

S16. High resolution mass spectrum of experiment 2.2 (based on a five minutes average at mass peak).

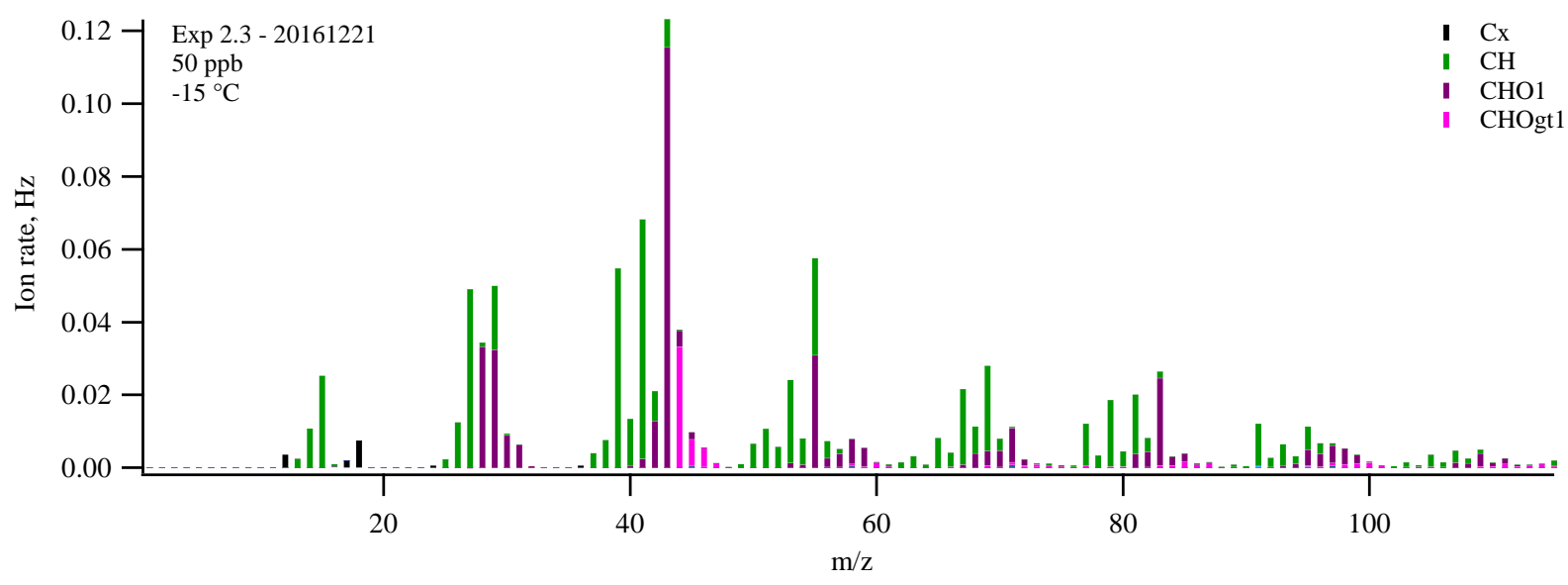

S17. High resolution mass spectrum of experiment 2.3 (based on a five minutes average at mass peak).

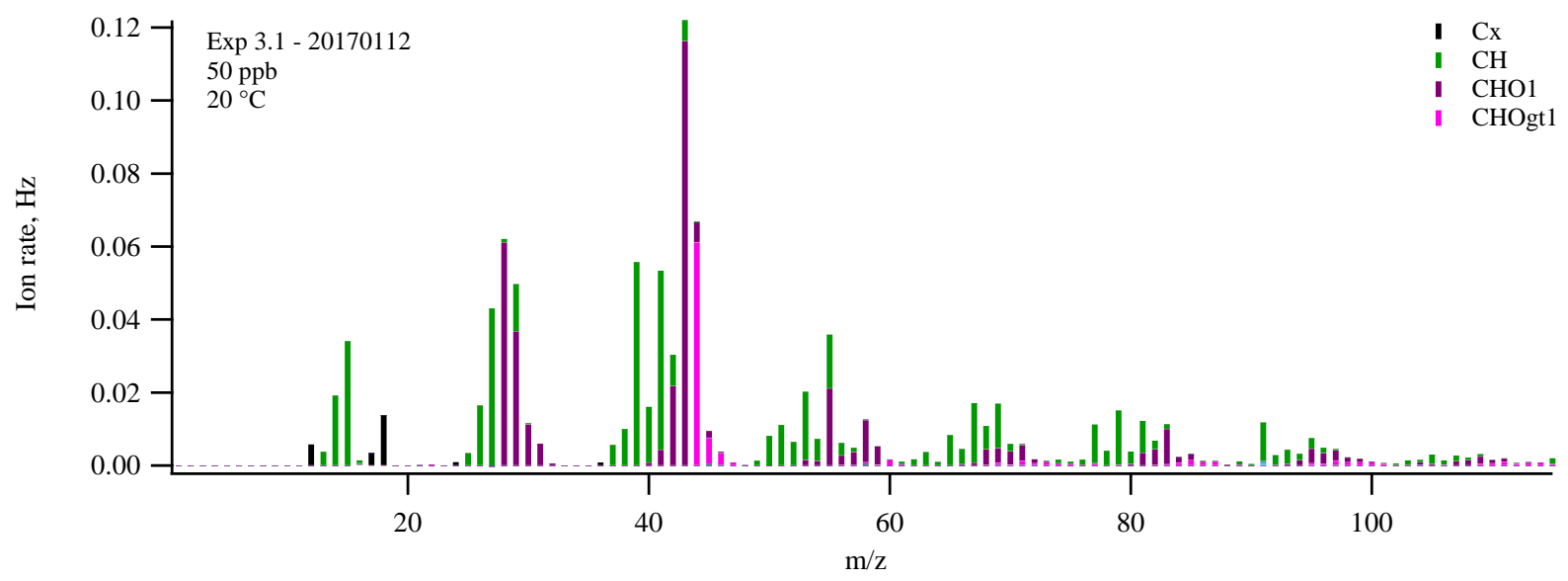

S18. High resolution mass spectrum of experiment 3.1 (based on a five minutes average at mass peak). 


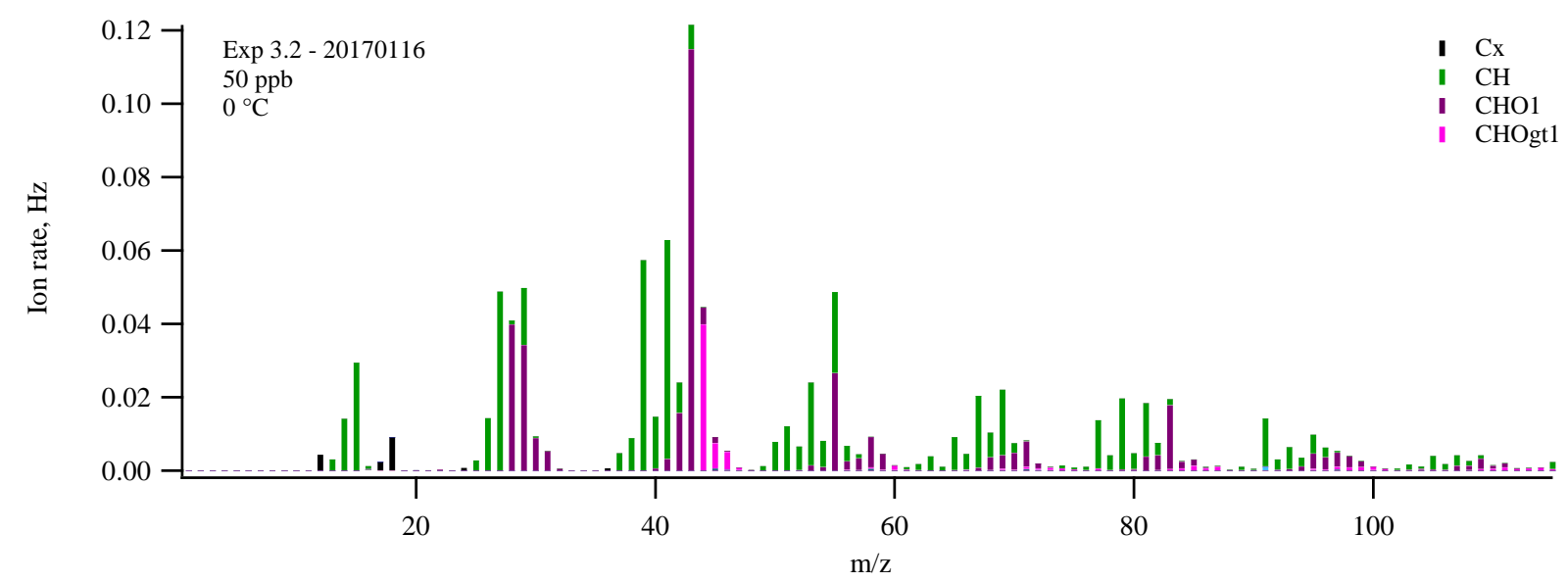

S19. High resolution mass spectrum of experiment 3.2 (based on a five minutes average at mass peak).

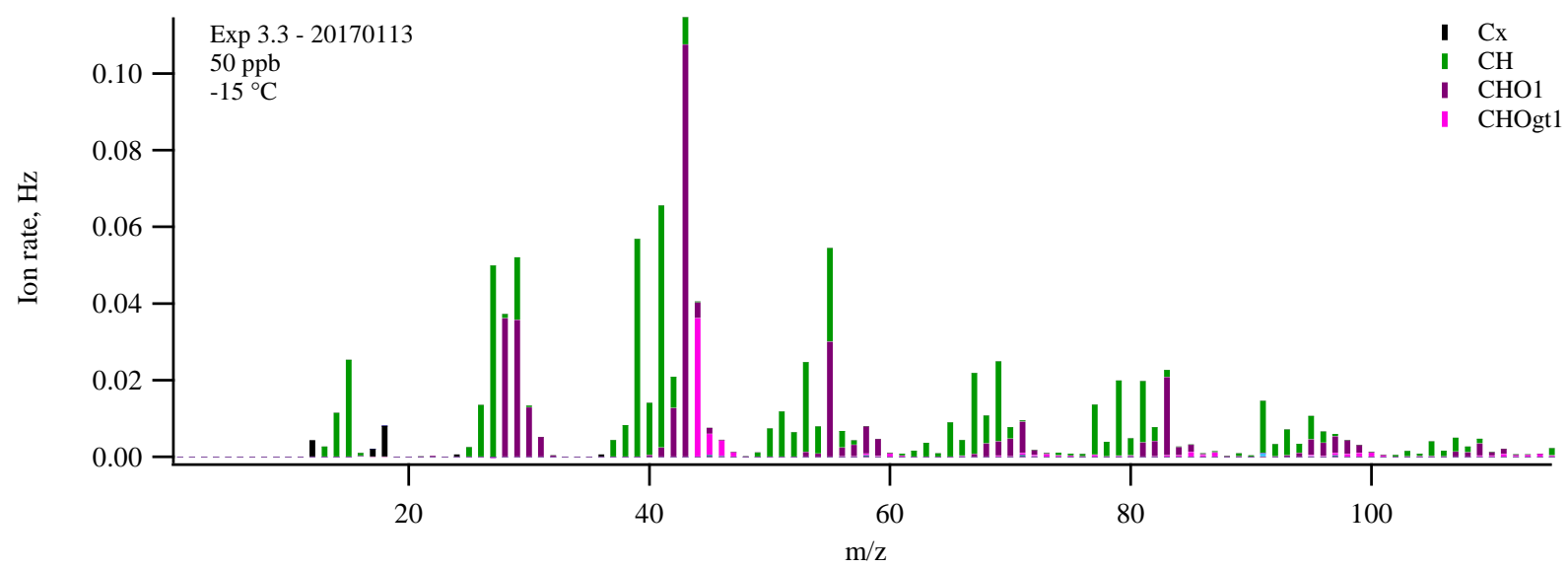

S20. High resolution mass spectrum of experiment 3.3 (based on a five minutes average at mass peak). 